\title{
Insulin-like growth factor 1/insulin-like growth factor 1 receptor signaling protects against cell apoptosis through the PI3K/AKT pathway in glioblastoma cells
}

\author{
MINGSHI ZHANG ${ }^{1}$, JINRUI LIU ${ }^{1}$, MINGJUN LI ${ }^{1}$, SHIHUA ZHANG $^{1}$, \\ YANMEI LU ${ }^{1}$, YANQIU LIANG ${ }^{2}, \mathrm{KAI} \mathrm{ZHAO}^{3}$ and YINGFU LI $^{1}$ \\ Departments of ${ }^{1}$ Neurosurgery and ${ }^{2}$ Radiology, The First Affiliated Hospital of Jiamusi University; \\ ${ }^{3}$ Graduate School, Jiamusi University, Jiamusi, Heilongjiang 154002, P.R. China
}

Received May 16, 2016; Accepted March 24, 2017

DOI: $10.3892 /$ etm.2018.6336

\begin{abstract}
Glioblastoma multiforme (GBM) is a malignant tumor caused by complex pathological mechanisms, and is characterized by a high rate of cancer-related mortality and poor patient prognosis. Overgrowth of cancer cells, which results from the inhibition of cell apoptosis and/or the promotion of cell proliferation, leads to the progression of GBM. Therefore, studies into the regulatory mechanisms of cancer cell growth in GBM are required to identify potential therapeutic targets and improve treatment for GBM. In the present study, the role of insulin-like growth factor 1 (IGF1)/IGF1 receptor (IGF1R) signaling in the survival of GBM cells was evaluated. It was observed that IGF1 significantly inhibited the intrinsic and extrinsic pathways of apoptosis $(\mathrm{P}<0.05)$, and overexpression of IGF1R significantly promoted the survival of GBM cells $(\mathrm{P}<0.05)$. Moreover, both exogenous IGF1 and overexpression of IGF1R promoted the phosphorylation of protein kinase $\mathrm{B}$ (AKT), and inhibition of the phosphoinositide 3-kinase (PI3K)/AKT pathway significantly attenuated the inhibitory effects of IGF1/IGF1R on GBM apoptosis $(\mathrm{P}<0.05)$. Collectively, these findings indicate that IGF1/IGF1R promotes the survival of GBM cells through activation of the PI3K/AKT pathway. Therefore, inhibition of IGF1/IGF1R may be a viable therapeutic strategy to suppress the progression of GBM.
\end{abstract}

\section{Introduction}

Glioblastoma multiforme (GBM) originates from glial cells and is the most prevalent and critical form of brain cancer (1).

Correspondence to: Dr Yingfu Li, Department of Neurosurgery, The First Affiliated Hospital of Jiamusi University, 348 Dexiang Road, Jiamusi, Heilongjiang 154002, P.R. China

E-mail: yingfulijd@tom.com

Key words: insulin-like growth factor, apoptosis, glioblastoma multiforme, protein kinase B pathway
GBM cells are characterized by their propensity to invade surrounding brain tissue adjacent to the main tumor mass (2). Although surgical resection combined with radiotherapy and/or chemotherapy is currently used as a standard treatment for GBM, the median survival rate of patients with GBM is $<15$ months $(3,4)$. Tumor recurrence, as a primary reason for the high mortality rate of GBM patients, is principally caused by residual tumor cells that remain within tissues following various treatments (5). Cellular apoptosis is negatively correlated with cell growth, and the inhibition of cell apoptosis is primarily responsible for cancer cell survival. Therefore, induction of apoptosis is considered to be a potential therapeutic strategy for the eradication or suppression of cancer cell growth and tumor progression (6,7). However, the mechanism responsible for regulating cancer cell survival in GBM remains unknown and warrants investigation.

Results suggest that insulin-like growth factor 1 (IGF1) and its receptor tyrosine kinase [insulin-like growth factor 1 receptor (IGF1R) are key regulators in the development and progression of cancer (8). Previous studies have demonstrated that the IGF1/IGF1R pathway is involved in regulating tumorigenesis, cell growth and metastasis in many cancers, and that some physiological functions, including cell cycle progression, apoptosis and differentiation, are associated with the IGF1/IGF1R pathway $(9,10)$. In colon cancer cells, it has also been documented that activation of IGF1/IGF1R induced by incubation with tumor necrosis factor lead to cellular resistance to apoptosis (11). Furthermore, inhibition of the IGF1/IGF1R pathway may reduce tumorigenesis and attenuate tumor progression through the induction of apoptosis in cancer cells (12). However, the role of IGF1/IGF1R signaling in the survival of GBM cells and the corresponding molecular mechanisms are not well understood.

In the present study, it was observed that exogenous IGF1 or overexpression of IGF1R protected against apoptosis and promoted the survival of GBM cells. Mechanistic assays also indicated that the inhibitory effects of IGF1/IGF1R on GBM apoptosis were mediated by the phosphoinositide 3-kinase (PI3K)/protein kinase B (AKT) pathway. These results suggest that targeting of IGF1/IGF1R signaling may aid to improve the efficacy of treatments for GBM. 


\section{Materials and methods}

Cell culture. The glioblastoma cell line U87 was obtained from the American Type Culture Collection (Manassas, VA, USA). U87 cells were maintained in an incubator at $37^{\circ} \mathrm{C}$ and $5 \% \mathrm{CO}_{2}$. The cells were cultured in Dulbecco's modified Eagle's medium (DMEM) with 10\% fetal bovine serum (FBS) and $10^{5} \mathrm{U} / 1$ penicillin-streptomycin (all from Gibco; Thermo Fisher Scientific, Inc., Waltham, MA, USA) for three days.

Cell viability assay. U87 cells were seeded into 96-well plates in DMEM with $10 \%$ FBS at a density of $5 \times 10^{3}$ cells/well and incubated at $37^{\circ} \mathrm{C}$ for $12 \mathrm{~h}$. Cells were then treated at $37^{\circ} \mathrm{C}$ with $200 \mu \mathrm{M} \mathrm{H}_{2} \mathrm{O}_{2}$ (Sigma-Aldrich; Merck KGaA, Darmstadt, Germany), 2.5, 5, 10 and 20 ng exogenous IGF (PeproTech, Rocky Hill, NJ, USA), $10 \mu \mathrm{M}$ wortmannin (Beyotime Institute of Biotechnology, Haimen, China) and $2 \mu \mathrm{g}$ IGF1R plasmid (Addgene, Inc., Cambridge MA, USA) for $48 \mathrm{~h}$ (13). U87 cells cultured in 10\% FBS DMEM treated with PBS were used as control. Following treatment, cell proliferation was assessed using a Cell Counting Kit 8 (CCK8) Cell Proliferation Assay kit (Invitrogen; Thermo Fisher Scientific, Inc.), according to the manufacturer's instructions. Briefly, CCK8 reagent $(5 \mu \mathrm{l})$ was added to each well and incubated at $37^{\circ} \mathrm{C}$ for $2 \mathrm{~h}$, and the number of viable cells was calculated from absorbance measurements at $450 \mathrm{~nm}$.

Lactate dehydrogenase $(\mathrm{LDH})$ release assay. The release of LDH from U87 cells cultured in 10\% FBS DMEM was measured to determine cell viability according to the manufacturer's protocol of a CytoTox-One ${ }^{\mathrm{TM}}$ Homogenous Membrane Integrity Assay kit (Promega Corporation, Madison, WI, USA). Cells were seeded at a density of 5,000 cells per well. Fluorescence (excitation at $480 \mathrm{~nm}$; emission maximum at 560-590 nm) was assessed using a Spectramax Gemini XS Microplate Spectrofluorometer (Molecular Devices LLC, Sunnyvale, CA, USA). The cytotoxicity of treated U87 cells was calculated as the relative increase in $\mathrm{LDH}$ compared with that of untreated control cells.

Caspase- 3 activity assay. A total of $5 \times 10^{6} \mathrm{U} 87$ cells were lysed in caspase buffer [10 mM Tris- $\mathrm{HCl}, 10 \mathrm{mM} \mathrm{NaH}_{2} \mathrm{PO}_{4}$, $130 \mathrm{mM} \mathrm{NaCl}, 1 \%$ (v/v) Triton X-100], and extracts were clarified by centrifugation at $16,099 \mathrm{xg}$ for $10 \mathrm{~min}$ at $4^{\circ} \mathrm{C}$. Protein concentration was assessed using the Bradford Protein Assay kit (Beyotime Institute of Biotechnology), and caspase activity was assayed using a fluorometric method with a luminescence spectrometer (Sinergy HT; BioTek Instruments, Inc., Winooski, VT, USA) at $460 \mathrm{~nm}$ as previously described (14). After measuring the concentrations, Acetyl tetrapeptide coupled to 4-methycoumaryl-7-amide (Ac-DEVD-AMC substrate; PeptaNova GmdH, Sandhausen, Germany), used as a fluorogenic substrate for caspase-3, was mixed with the extracts for $\sim 4 \mathrm{~h}$ at $37^{\circ} \mathrm{C}$. Caspase activity was calculated as absorbance $/ \mu \mathrm{g}$ protein.

Western blot analysis. A total of $5 \times 10^{6} \mathrm{U} 87$ cells were lysed in extraction buffer (Tris $50 \mathrm{mM}$, pH 7.4, NaCl $150 \mathrm{mM}$, Triton $\mathrm{X}-1001 \%$, EDTA $1 \mathrm{mM}$, and PMSF $2 \mathrm{mM}$ ). Extracts were clarified by centrifugation at $16,099 \times \mathrm{g}$ for $10 \mathrm{~min}$ at $4^{\circ} \mathrm{C}$, and protein concentrations were determined using a Bradford Protein Assay kit (Beyotime Institute of Biotechnology). A total of $50 \mu \mathrm{g}$ cell protein was loaded per lane of a $12 \%$ SDS PAGE gel for separation by electrophoresis. Separated proteins were then transblotted onto nitrocellulose membranes (Whatman, Inc., Florham Park, NJ, USA) and immunoprobed with primary antibodies against IGF1R (ab39675; Abcam, Cambridge, MA, USA; 1:1,000), Fas ligand (sc-6237), B-cell lymphoma 2 (Bcl-2; sc-492), Akt (sc-1618), phosphorylated (p)-Akt (sc-33437) and beta-actin (sc-1616; Santa Cruz Biotechnology, Inc., Dallas, CA, USA; 1:8,000 for beta-actin and 1:500 for the remaining antibodies) at $4^{\circ} \mathrm{C}$ overnight. The blots were incubated with secondary antibodies of horseradish peroxidase conjugated (HRP) mouse anti-goat IgG (sc-2354) or mouse anti-rabbit IgG-HRP (sc-2357; both Santa Cruz Biotechnology, Inc.; 1:5,000) at room temperature for $1 \mathrm{~h}$, then reacted with an enhanced chemiluminescence substrate (Pierce; Thermo Fisher Scientific, Inc.). Resulting band intensities were recorded on an X-ray film. Quantity One software v4.62 (Bio-Rad Laboratories, Inc., Hercules, CA, USA) was utilized to assess the protein bands, and all experiments were repeated three times.

Statistical analysis. Statistical analysis was performed using SPSS version 13.0 software (SPSS Inc., Chicago, IL, USA). Data were expressed as the mean \pm standard error of the mean of three independent experiments, and a Student's t-test was used to determine the statistical significance of results. Differences were considered to be significant when $\mathrm{P}<0.05$.

\section{Results}

IGF1 promotes survival and suppresses apoptosis in GBM cells. To detect the role of IGF1 in the survival of GBM cells, $200 \mu \mathrm{M} \mathrm{H}_{2} \mathrm{O}_{2}$ was used to establish a cell apoptotic model. Different concentrations of IGF1 $(2.5,5,10$ and $20 \mathrm{ng})$ were initially administered to determine the optimal concentration of IGF1 for subsequent experiments in U87 cells. Results of a CCK8 assay indicated that treatment with $\mathrm{H}_{2} \mathrm{O}_{2}$ significantly decreased the viability of U87 cells compared with controls $(\mathrm{P}<0.05$; Fig. 1A), while IGF1 concentrations of 10 and $20 \mathrm{ng}$ significantly restored cell viability (both $\mathrm{P}<0.05$; Fig. $1 \mathrm{~A}$ ). Similarly, a cell death assay demonstrated that LDH release was markedly enhanced by $200 \mu \mathrm{M} \mathrm{H}_{2} \mathrm{O}_{2}$, while 10 and $20 \mathrm{ng}$ IGF1 significantly attenuated the release of LDH induced by $\mathrm{H}_{2} \mathrm{O}_{2}$ (both $\mathrm{P}<0.05$; Fig. 1B). These results suggest that IGF1 promotes cell growth and inhibits cell death at doses of $\geq 10 \mathrm{ng}$, indicating that the optimal dose of IGF1 in regulating the survival of GBM cells is $10 \mathrm{ng}$.

IGF1 inhibits the extrinsic and intrinsic pathways of apoptosis. To identify the role of IGF1 in apoptosis, it was determined whether the intrinsic and/or extrinsic pathways of apoptosis were affected by IGF1. Key molecules in each pathway were detected in response to IGF1 treatment. Caspse-3, a final executor of cell apoptosis, is activated by various stimuli in the process of cell apoptosis (15). Expression of Fas ligand is specifically increased during the extrinsic pathway of apoptosis, and $\mathrm{Bcl}-2$, as an anti-apoptotic protein localized to the outer mitochondrial membrane, is involved in the intrinsic 


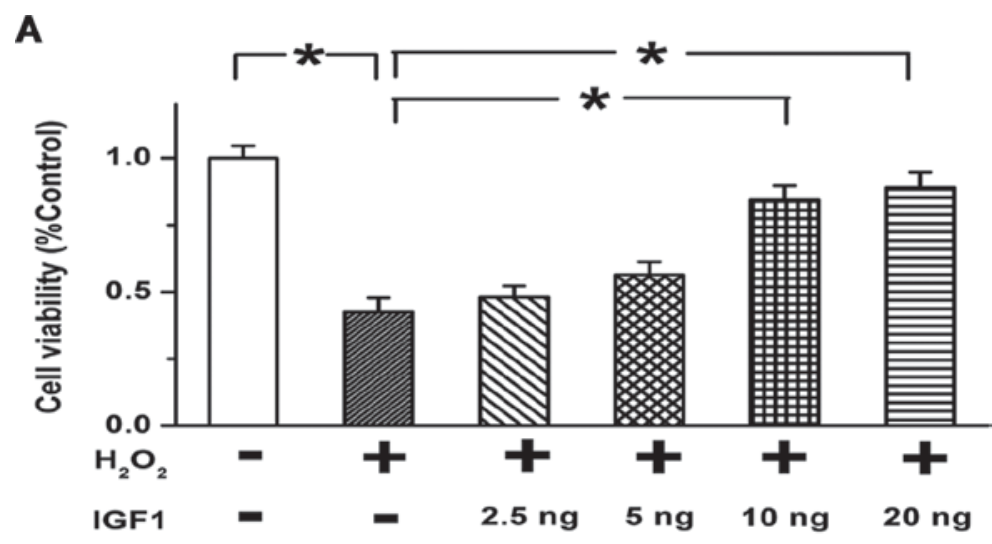

B

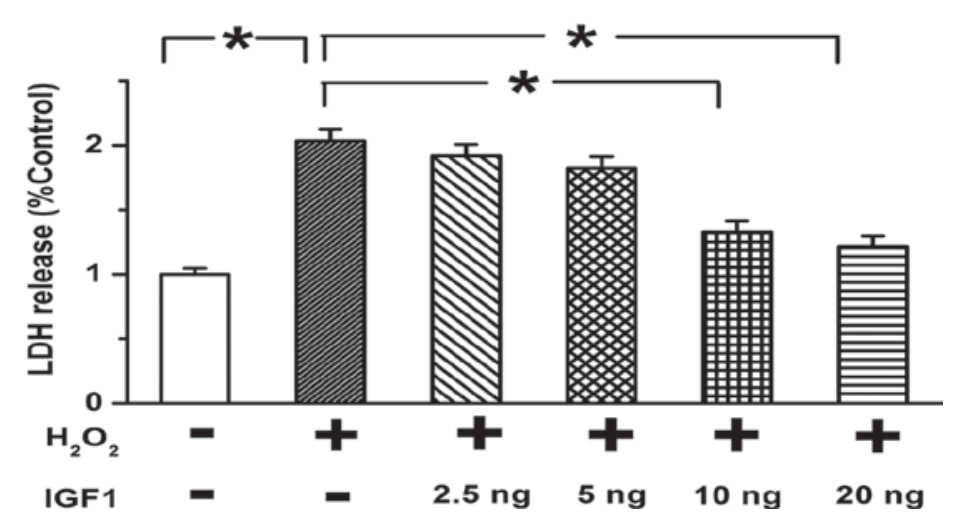

Figure 1. IGF1 promoted growth and inhibited apoptosis in glioblastoma multiforme cells. (A) IGF1 restored the decrease in cell viability induced by $200 \mu \mathrm{M}$ $\mathrm{H}_{2} \mathrm{O}_{2}$ at doses of $\geq 10 \mathrm{ng}$. (B) IGF1 attenuated the release of LDH induced by $\mathrm{H}_{2} \mathrm{O}_{2}$ at doses of $\geq 10 \mathrm{ng}$. Data are presented as the mean \pm standard error of the mean of three independent experiments. " $\mathrm{P}<0.05$. IGF1, insulin-like growth factor 1; LDH, lactate dehydrogenase.

pathway of cell apoptosis (15). The present results demonstrated that caspase- 3 was significantly activated in U87 cells following $\mathrm{H}_{2} \mathrm{O}_{2}$ treatment ( $\mathrm{P}<0.05$ vs. control), and that this effect was significantly attenuated by $10 \mathrm{ng}$ IGF1 $(\mathrm{P}<0.05$; Fig. 2A). Furthermore, $\mathrm{H}_{2} \mathrm{O}_{2}$ increased the expression of Fas and decreased the expression of $\mathrm{Bcl}-2$, while treatment with IGF1 reversed these changes (Fig. $2 \mathrm{~B}$ and $\mathrm{C}$ ). These results indicate that IGF1 may promote the survival of GBM cells.

Overexpression of IGFIR inhibits apoptosis and promotes survival in GBM cells. Stable overexpression of IGF1R was established in U87 cells by lentiviral infection. As depicted in Fig. 3A, the efficiency of IGF1R overexpression was verified by western blot analysis. A subsequent CCK8 assay indicated that the viability of $\mathrm{U} 87$ cells was significantly suppressed by $\mathrm{H}_{2} \mathrm{O}_{2}$ treatment $(\mathrm{P}<0.05$ vs. control), which was significantly attenuated by overexpression of IGF1R ( $<<0.05$; Fig. 3B). Similarly, the elevated rate of cell death induced by $\mathrm{H}_{2} \mathrm{O}_{2}(\mathrm{P}<0.05$ vs control) was significantly reduced by overexpression of IGF1R $(\mathrm{P}<0.05)$, as determined by an LDH release assay (Fig. 3C). Furthermore, the increased activity of caspase-3 induced by $\mathrm{H}_{2} \mathrm{O}_{2}$ ( $\mathrm{P}<0.05$ vs. control) was significantly reduced by IGF1R overexpression $(\mathrm{P}<0.05$; Fig. 3D). These results suggest that activation of the IGF1/IGF1R pathway suppresses apoptosis and promotes survival in GBM cells.

IGF1/IGF1R inhibits cell apoptosis by activating the PI3K/AKT pathway. The PI3K/AKT pathway is a critical pathway in the regulation of cell apoptosis. Therefore, it was determined whether a regulatory relationship existed between IGF1/IGF1R and the PI3K/AKT pathway in U87 cells. As depicted in Fig. 4A and B, it was observed that both exogenous IGF1 treatment and overexpression of IGF1R induced the phosphorylation of AKT. Furthermore, wortmannin, as an inhibitor of the PI3K/AKT pathway (16), was used to determine the role of PI3K/AKT in the inhibition of cell apoptosis by IGF1/IGF1R. It was observed that the increases in cell viability induced by exogenous IGF1 or IGF1R overexpression were significantly reversed by $10 \mu \mathrm{M}$ wortmannin $(\mathrm{P}<0.05$; Fig. 4C and D). Furthermore, inhibition of caspase- 3 activation by IGF1/IGF1R was significantly attenuated by wortmannin $(\mathrm{P}<0.05$; Fig. $4 \mathrm{E}$ and $\mathrm{F})$. Therefore, the inhibitory effects of IGF1/IGF1R on GBM apoptosis may be mediated by PI3K/AKT signaling.

\section{Discussion}

It has been established that the progression and development of glioblastoma is primarily due to the overgrowth of cancer cells, determined by the balance between the growth and death of cells (17). Previous results have indicated that a dysfunction in cell apoptosis may be responsible for the initiation of many human diseases, including glioblastoma (18). Inhibition of cell apoptosis is frequently observed in the tissues of glioblastoma patients, and thus the regulation of cell apoptosis is considered to be a potential strategy in preventing the progression 
A

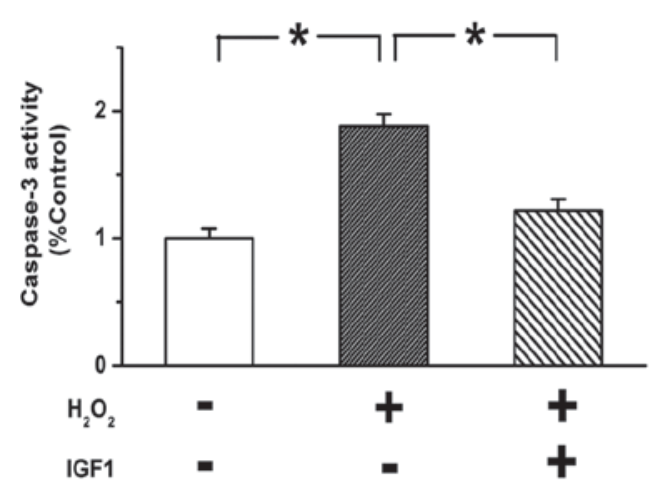

C

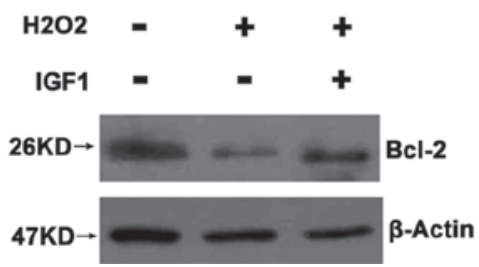

B

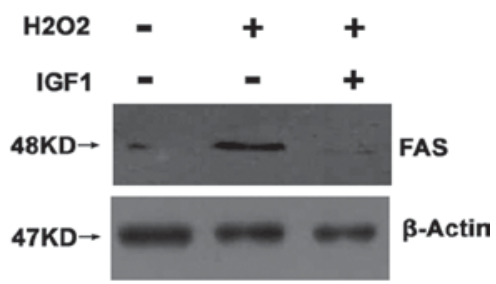

Figure 2. IGF1 inhibited the extrinsic and intrinsic pathways of apoptosis in glioblastoma multiforme cells. (A) IGF1 blocked activation of caspase-3 induced by $\mathrm{H}_{2} \mathrm{O}_{2}$ in U87 cells. (B) Upregulation in Fas ligand induced by $\mathrm{H}_{2} \mathrm{O}_{2}$ was antagonized by IGF1. (C) Downregulation in Bcl-2 induced by $\mathrm{H}_{2} \mathrm{O}_{2}$ was reversed by IGF1. Data are presented as the mean \pm standard error of the mean of three independent experiments. "P<0.05. IGF1, insulin-like growth factor 1 ; Bcl-2, B-cell lymphoma 2; U87, glioblastoma multiforme cell line.

A

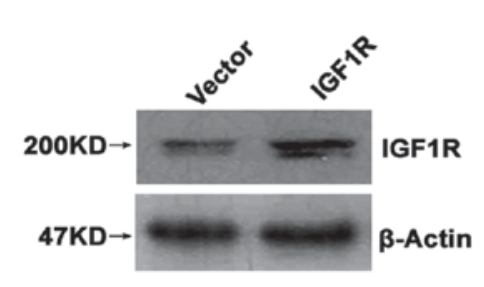

C

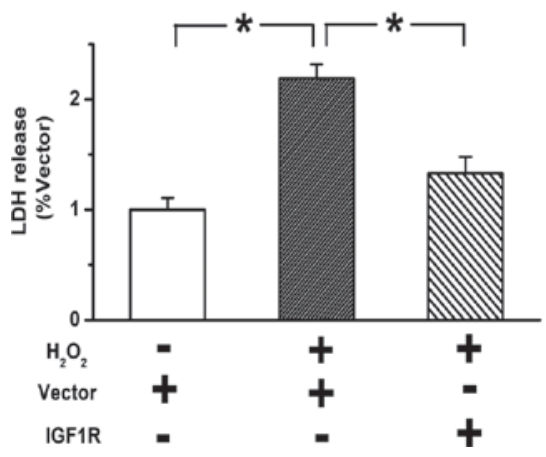

B
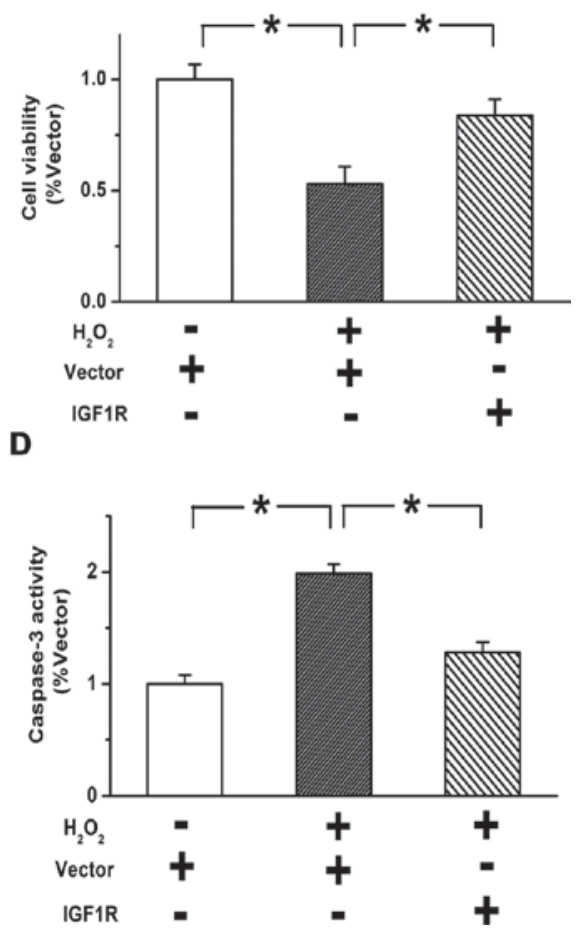

Figure 3. Overexpression of IGF1R inhibited apoptosis and promoted survival in glioblastoma multiforme cells. (A) Expression of IGF1R was upregulated by transfection with an IGF1R overexpression vector in U87 cells. (B) Overexpression of IGF1R reversed the decrease in cell viability induced by $\mathrm{H}_{2} \mathrm{O}_{2}$. (C) $\mathrm{H}_{2} \mathrm{O}_{2}$-induced cell death was attenuated by overexpression of IGF1R. (D) Activation of caspase-3 induced by $\mathrm{H}_{2} \mathrm{O}_{2}$ was suppressed by IGF1R overexpression. Data are presented as the mean \pm standard error of the mean of three independent experiments. ${ }^{*} \mathrm{P}<0.05$. IGF1R, insulin-like growth factor 1 receptor; U87, glioblastoma multiforme cell line.

of glioblastoma (19). Therefore, studies into the regulatory mechanisms of apoptosis in GBM cells are required to improve the efficacy of molecular therapy. In the present study, it was observed that IGF1/IGF1R protected against apoptosis and 
A

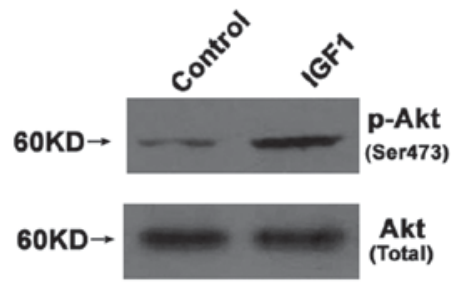

C

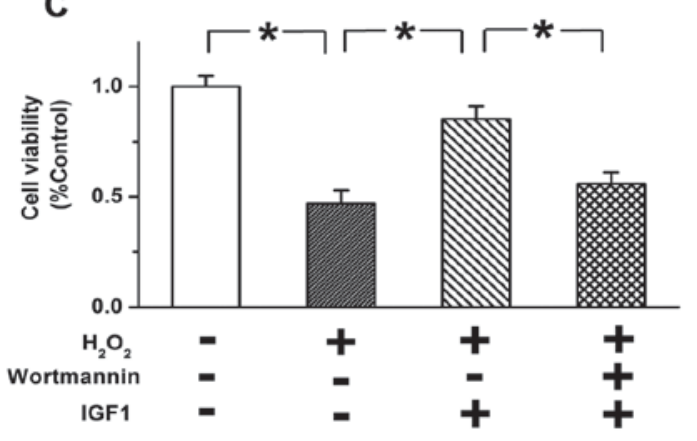

$\mathbf{E}$

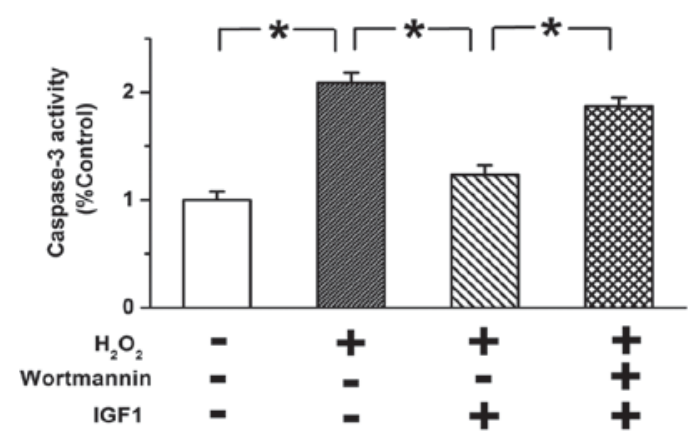

B

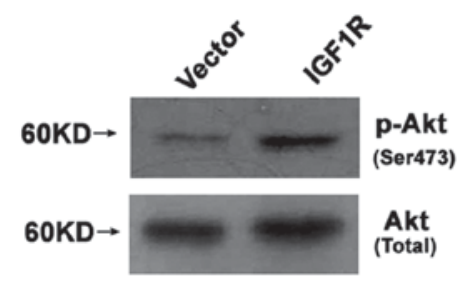

D

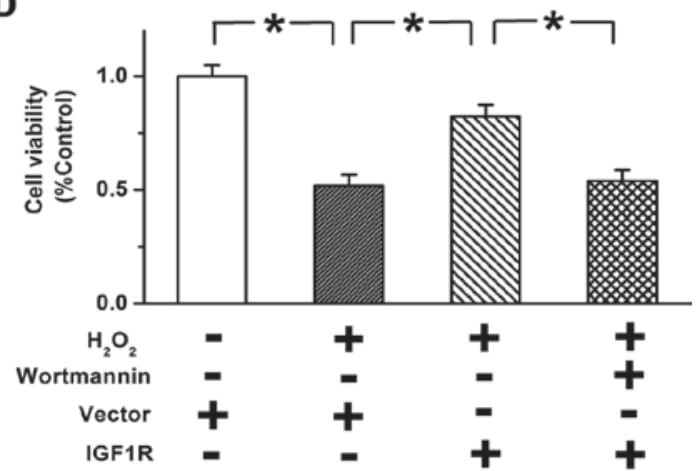

$\mathbf{F}$

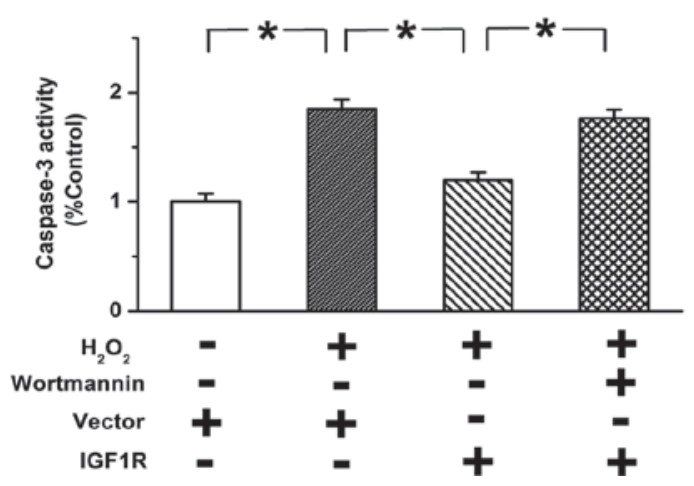

Figure 4. Inhibitory effects of IGF1/IGF1R on cell apoptosis were mediated by the PI3K/AKT pathway. (A) IGF1 treatment induced the phosphorylation of AKT in U87 cells. (B) Phosphorylation of AKT was increased by overexpression of IGF1R. (C and D) The increases in cell viability induced by (C) exogenous IGF1 or (D) IGF1R overexpression were reversed by inhibition of the PI3K/AKT pathway. (E) Inhibition of caspase-3 activity by IGF1 was weakened by wortmannin. (F) Inhibition of caspase-3 activity by IGF1R overexpression was attenuated by inhibition of the PI3K/AKT pathway. Data are presented as the mean \pm standard error of the mean of three independent experiments. ${ }^{*}<<0.05$. IGF1, insulin-like growth factor 1 ; IGF1R, insulin-like growth factor 1 receptor; PI3K, phosphoinositide 3-kinase inhibitor; U87, glioblastoma multiforme cell line; p-, phosphorylation.

promoted the survival of GBM cells, and that the regulatory effects of IGF1/IGF1R on apoptosis were potentially mediated by PI3K/AKT signaling.

Previous studies have demonstrated that IGF1R, as a key regulator of mitogenesis and tumorigenicity, participates in regulating cell transformation, cell growth and cell cycle progression $(20,21)$. IGF1 is a specific ligand of IGF1R, and upon binding to IGF1R, activates a cascade of intracellular molecular pathways, which may occur during the development and progression of a number of diseases, including cancer (22). IGF1/IGF1R and downstream targets are important in the regulation of cell transformation (23), invasion (24), tumor metastasis (25) and cell survival (9). Although overexpression of IGF1 and IGF1R has been observed in a subset of cancer tissues from patients with GBM (26), the consequences of IGF1/IGF1R overexpression on the survival of GBM cells and the corresponding molecular mechanisms are not well understood. In the present study, it was observed that IGF1 promoted cell survival and suppressed cell death at doses of $\geq 10 \mathrm{ng}$. Furthermore, both exogenous IGF1 and IGF1R overexpression inhibited the intrinsic and extrinsic pathways of apoptosis in GBM cells. These results indicated that activation of IGF1/IGF1R promoted the survival of GBM cells by inhibiting apoptosis.

The PI3K/AKT pathway, as a critical pro-survival signaling pathway, modulates cell growth, proliferation, apoptosis and survival in a number of cell types (27). It has been documented that increased phosphorylation of AKT at Ser/Thr sites was associated with the inhibition of cell apoptosis (28). Moreover, aberrant activation of the PI3K/AKT pathway has been observed in a number of tumor tissues, including GBM, and inhibitors of the PI3K/AKT pathway have been investigated as a potential anticancer therapy (29). However, the regulatory mechanisms underlying the PI3K/AKT pathway in the progression of GBM remain unknown. In the present study, it was demonstrated that IGF1/IGF1R promoted the activation of PI3K/AKT signaling in GBM cells. Specifically, the results indicated that both exogenous IGF1 and IGF1R overexpression 
led to increased phosphorylation of AKT. Furthermore, the inhibitory effects of IGF1/IGF1R on the apoptosis of GBM cells were attenuated by inhibition of the PI3K/AKT pathway. These results suggested that IGF1/IGF1R promotes the growth and survival of GBM cells, at least in part through the PI3K/AKT pathway.

In conclusion, the present study indicated that IGF1/IGF1R promoted cell survival and inhibited cell apoptosis through activation of the PI3K/AKT pathway. These results have identified a potential regulatory mechanism underlying the growth of cancer cells in GBM, and targeting of IGF1/IGF1R may aid to improve the efficacy of treatment for GBM.

\section{References}

1. Gurney JG and Kadan-Lottick N: Brain and other central nervous system tumors: Rates, trends, and epidemiology. Curr Opin Oncol 13: 160-166, 2001.

2. Henriksson R, Asklund T and Poulsen HS: Impact of therapy on quality of life, neurocognitive function and their correlates in glioblastoma multiforme: A review. J Neurooncol 104: 639-646, 2011.

3. Van Meir EG, Hadjipanayis CG, Norden AD, Shu HK, Wen PY and Olson JJ: Exciting new advances in neuro-oncology: The avenue to a cure for malignant glioma. CA Cancer J Clin 60 : 166-193, 2010.

4. Stupp R, Hegi ME, Gilbert MR and Chakravarti A: Chemoradiotherapy in malignant glioma: Standard of care and future directions. J Clin Oncol 25: 4127-4136, 2007.

5. Wen PY and Kesari S: Malignant gliomas in adults. N Engl J Med 359: 492-507, 2008.

6. Wu L, Nam YJ, Kung G, Crow MT and Kitsis RN: Induction of the apoptosis inhibitor ARC by Ras in human cancers. J Biol Chem 285: 19235-19245, 2010.

7. Wang Y, Chen D, Qian H, Tsai YS, Shao S, Liu Q, Dominguez D and Wang Z: The splicing factor RBM4 controls apoptosis proliferation, and migration to suppress tumor progression. Cancer Cell 26: 374-389, 2014.

8. Wang Y and Sun Y: Insulin-like growth factor receptor-1 as an anti-cancer target: Blocking transformation and inducing apoptosis. Curr Cancer Drug Targets 2: 191-207, 2002.

9. Resnicoff M, Abraham D, Yutanawiboonchai W, Rotman HL, Kajstura J, Rubin R, Zoltick P and Baserga R: The insulin-like growth factor I receptor protects tumor cells from apoptosis in vivo. Cancer Res 55: 2463-2469, 1995.

10. Dupont $\mathbf{J}$ and LeRoith D: Insulin and insulin-like growth factor I receptors: Similarities and differences in signal transduction. Horm Res 55 (Suppl 2): S22-S26, 2001.

11. Remacle-Bonnet MM, Garrouste FL, Heller S, André F, Marvaldi JL and Pommier GJ: Insulin-like growth factor-I protects colon cancer cells from death factor-induced apoptosis by potentiating tumor necrosis factor alpha-induced mitogen-activated protein kinase and nuclear factor kappaB signaling pathways. Cancer Res 60: 2007-2017, 2000.

12. Peruzzi F, Prisco M, Dews M, Salomoni P, Grassilli E, Romano G, Calabretta B and Baserga R: Multiple signaling pathways of the insulin-like growth factor 1 receptor in protection from apoptosis. Mol Cell Biol 19: 7203-7215, 1999.

13. Entingh-Pearsall A and Kahn CR: Differential roles of the insulin and insulin-like growth factor-I (IGF-I) receptors in response to insulin and IGF-I. J Biol Chem 279: 38016-38024, 2004.
14. Yasuda Y, Saito M, Yamamura T, Yaguchi T and Nishizaki T: Extracellular adenosine induces apoptosis in Caco-2 human colonic cancer cells by activating caspase-9/-3 via A(2a) adenosine receptors. J Gastroenterol 44: 56-65, 2009.

15. Ma J, Liang S, Wang Z, Zhang L, Jiang J, Zheng J, Yu L, Zheng X, Wang R and Zhu D: ROCK pathway participates in the processes that 15-hydroxyeicosatetraenoic acid (15-HETE) mediated the pulmonary vascular remodeling induced by hypoxia in rat. J Cell Physiol 222: 82-94, 2010.

16. Gopinath S, Alapati K, Malla RR, Gondi CS, Mohanam S, Dinh DH and Rao JS: Mechanism of p27 upregulation induced by downregulation of cathepsin B and uPAR in glioma. Mol Oncol 5: 426-437, 2011.

17. Gomez GG, Volinia S, Croce CM, Zanca C, Li M, Emnett R, Gutmann DH, Brennan CW, Furnari FB and Cavenee WK: Suppression of microRNA-9 by mutant EGFR signaling upregulates FOXP1 to enhance glioblastoma tumorigenicity. Cancer Res 74: 1429-1439, 2014.

18. Sawa H, Murakami H, Kumagai M, Nakasato M, Yamauchi S, Matsuyama N, Tamura Y, Satone A, Ide W, Hashimoto I and Kamada H: Histone deacetylase inhibitor, FK228, induces apoptosis and suppresses cell proliferation of human glioblastoma cells in vitro and in vivo. Acta Neuropathol 107: 523-531, 2004.

19. Ziegler DS, Wright RD, Kesari S, Lemieux ME, Tran MA, Jain M, Zawel L and Kung AL: Resistance of human glioblastoma multiforme cells to growth factor inhibitors is overcome by blockade of inhibitor of apoptosis proteins. J Clin Invest 118: 3109-3122, 2008.

20. DeAngelis T, Ferber A and Baserga R: Insulin-like growth factor I receptor is required for the mitogenic and transforming activities of the platelet-derived growth factor receptor. J Cell Physiol 164: 214-221, 1995.

21. Coppola D, Ferber A, Miura M, Sell C, D'Ambrosio C, Rubin R and Baserga R: A functional insulin-like growth factor I receptor is required for the mitogenic and transforming activities of the epidermal growth factor receptor. Mol Cell Biol 14: 4588-4595, 1994.

22. Pollak M: Insulin and insulin-like growth factor signalling in neoplasia. Nat Rev Cancer 8: 915-928, 2008.

23. Sell C, Dumenil G, Deveaud C, Miura M, Coppola D, DeAngelis T, Rubin R, Efstratiadis A and Baserga R: Effect of a null mutation of the insulin-like growth factor I receptor gene on growth and transformation of mouse embryo fibroblasts. Mol Cell Biol 14: 3604-3612, 1994.

24. Zeigler ME, Krause S, Karmiol S and Varani J: Growth factor-induced epidermal invasion of the dermis in human skin organ culture: Dermal invasion correlated with epithelial cell motility. Invasion Metastasis 16: 3-10, 1996.

25. Long L, Rubin R, Baserga R and Brodt P: Loss of the metastatic phenotype in murine carcinoma cells expressing an antisense RNA to the insulin-like growth factor receptor. Cancer Res 55: 1006-1009, 1995.

26. Arcaro A: Targeting the insulin-like growth factor-1 receptor in human cancer. Front Pharmacol 4: 30, 2013.

27. Zhang L, Zhou F and ten Dijke P: Signaling interplay between transforming growth factor- $\beta$ receptor and PI3K/AKT pathways in cancer. Trends Biochem Sci 38: 612-620, 2013.

28. Edwards LA, Thiessen B, Dragowska WH, Daynard T, Bally MB and Dedhar S: Inhibition of ILK in PTEN-mutant human glioblastomas inhibits PKB/Akt activation, induces apoptosis, and delays tumor growth. Oncogene 24: 3596-3605, 2005.

29. Shingu T, Yamada K, Hara N, Moritake K, Osago H, Terashima M, Uemura T, Yamasaki T and Tsuchiya M: Synergistic augmentation of antimicrotubule agent-induced cytotoxicity by a phosphoinositide 3-kinase inhibitor in human malignant glioma cells. Cancer Res 63: 4044-4047, 2003. 